\title{
Maternal and infant health problems after normal childbirth: a randomised controlled study in Zambia
}

\author{
A B Ransjö-Arvidson, K Chintu, N Ng'andu, B Eriksson, B Susu, K Christensson, \\ V K Diwan
}

Department of Obstetrics and Gynaecology, University Teaching Hospital, Schools of Nursing and Medicine, Lusaka, University of Zambia, Zambia K Chintu

B Susu

Department of Public Health Sciences, Division of International Health Care Research (IHCAR), Karolinska Institutet, Stockholm, Sweden

A B Ransjö-Arvidson K Christensson

V K Diwan

Department of Community Medicine, School of Medicine, University of Zambia $\mathrm{N} \mathrm{Ng}$ 'andu

Nordic School of Public Health, Gothenburg, Sweden B Eriksson V K Diwan

Correspondence to: Anna-Berit Ransjö-Arvidson, Department of Public Health Sciences, Division of International Health Care Research (IHCAR), Karolinska Institutet, S-171 77 Stockholm, Sweden.

Accepted for publication 30 September 1997

\begin{abstract}
Study objectives-The main aim of the study was to discover if a midwife home visiting programme has a significant effect on the prevalence of health problems and breast feeding behaviour of mothers who delivered normally and their healthy fullterm newborn babies, during a period of 42 days after delivery. Another aim was to compare the mothers', the midwife's, and the doctor's findings of prevalence of health problems at the end of the puerperium period.
\end{abstract}

Design-A randomised controlled trial was carried out. One group of mothers and their infants were randomly allocated to a home visiting group (Group $A$ ); the other group (Group B) was only visited at day 42.

Setting-The study was carried out at the University Teaching Hospital (UTH) in Lusaka, the capital city of Zambia.

Participants-A total of 408 mothers who had a normal delivery and gave birth to a healthy fullterm infant, as assessed by the attending midwife, were randomised to two groups. Group A consisted of 208 mother/infant dyads who were visited by a midwife in their homes at days $3,7,28$, and 42 after delivery and Group $B$ consisted of 200 mother/infant dyads who were only visited at day 42 .

Main results-At day 42 an equal proportion $(30 \%)$ of mothers in both groups perceived that they had health problems. The prevalence of infant health problems in Group B was significantly higher $(p<0.01)$ as perceived by mothers. There were more mothers in Group B $(\mathbf{p}<0.01)$ perceiving insufficient milk production and giving supplementary feeding. At day 42, mothers in Group A (56\%) took more actions than mothers in Group B $(41 \%)$ to solve infant health problems $(p<0.03)$. In both groups the mothers' perceived own health problems, were significantly higher $(p<0.01)$ than those observed by the obstetrician and those observed by the midwife. The midwife found more infant health problems in Group B $(p<0.01)$ than in Group $A$ and more infants with health problems in both groups compared with the paediatrician's findings $(\mathbf{p}<0.01)$.

Conclusions-There was a significant difference between the mothers' reported health problems and the health problems identified by the midwife and the doctors. The study shows that a midwife home visit and individual health education to mothers, reduce the prevalence of infant health problems, and enables the mother to more often take action when an infant health problem is identified. There is a need to re-evaluate the midwifery training curriculums with the intention to include more infant management care.

(F Epidemiol Community Health 1998;52:385-391)

The concept of high risk pregnancy has been extensively discussed in recent years ${ }^{1}$ and programmes have been suggested to improve the coverage, content and quality of health service and support for the childbearing women. ${ }^{2-5}$ Less attention has been paid to describing the health and social situation of women as well as their concerns during the postpartum period. ${ }^{67}$ Information is limited on mother's self perceived health problems and self care actions for herself and her newborn child and the corresponding findings of the health workers during the postpartum period. Early hospital discharge after childbirth and follow up home visit programmes have been introduced in several countries. ${ }^{8}$ There has been little research on the contents and the effects on health of these programmes for normally delivered mothers and their newborns. ${ }^{9}$ It is assumed that postpartum women need more help and support and that home visits enhance a mother's utilisation of health care services at the postnatal clinic. ${ }^{10} 11$ The early postpartum period might also be the best period to discuss methods of family planning with the couple. In many developing countries, female relatives, often referred to as traditional birth attendants (TBAs), provide intra-and postpartum home care. These persons are only rarely included in health education efforts, which could be a cost effective measure to improve childbirth care. ${ }^{12} 13$

In Zambia, the high degree of urbanisation and institutional deliveries are exceptional for Sub-Saharan Africa. Approximately $76 \%$ of the deliveries in Lusaka, the capital of Zambia, are assisted either at the University Teaching Hospital (UTH) or at maternity centres with facilities for normal deliveries. ${ }^{14}$ Women who deliver without complications and interventions, for example, forceps or caesarean sections, are discharged from the UTH on average within eight to 12 hours after birth. After that the mother's first contact with the health care services for 
herself is with a postnatal clinic, usually after six weeks, and for the infant with a children's clinic. Attendance at postnatal clinics has usually been low. ${ }^{15}$

The main aim of this study was to evaluate the effect of a midwife home visiting (intervention) programme at $3,7,28$, and 42 days after birth on the prevalence of health problems and breast feeding behaviour of normally delivered mothers and healthy fullterm newborns at the end of puerperium. The other aim was to compare findings of health problems, as perceived by the mothers with those identified by the midwife and the doctor at the end of the puerperium.

\section{Methods}

The study was carried out between May 1989 and February 1992 at the UTH in Lusaka. According to the routines, approximately one hour after delivery, the mother and her healthy newborn were transferred from the labour ward to a postnatal ward with a special nursery. The study sample was selected from this ward.

\section{STUDY DESIGN}

Four hundred and eight mothers were allocated to two groups from this ward. Group A, comprising of 208 mother/infant dyads, were visited at home at $3,7,28$, and 42 days postpartum, while Group B, consisting of 200 dyads, were visited at home only at day 42 after birth. Two days per even week and three days per odd week six mothers fulfilling the inclusion criteria were randomly selected from the ward register book in the mornings. A second randomisation was done allocating three of these mother/infant dyads to home visiting intervention (Group A) and the other three to a control (Group B) group. The mother's participation was based on her informed consent about the details of the study and her accepting being visited a home several times during the puerperium. The mothers were asked to give detailed instructions about their living area and address. The mothers and their infants in both groups subsequently attended the postnatal clinic at UTH to be examined by physicians, mothers by an obstetrician and infants by a pediatrician, who were unaware to which group the mothers and infants belonged. The inclusion criteria were: the labour was assessed as "normal" by the attending midwife; gestational age 37-42 weeks, singleton birth, spontaneous vaginal delivery, vertex presentation, Apgar Score $\geqslant 8$ points at one minute after birth, no visible malformations of the newborn, and mother and newborn assessed by the midwife as being "healthy".

A pilot study of 10 mother/infant dyads was conducted to test the protocols and feasibility of the study. Two research teams with two trained research midwives in each team, carried out data collection. A detailed instruction guide was prepared for the research team. Data collection instruments were tested for reliability by an independent research midwife during the study period both at the postnatal ward and during the home visits.
Data were collected from antenatal and labour records, the variables used were; recommended investigations for haemoglobin, syphilis and immunisation of tetanus toxoid, done or not done, length of labour, type of lacerations including episiotomies, Apgar Score, and newborn birth weight. Before the discharge from the hospital ward, axillary temperature recording of the newborn was measured, using an electronic thermometer with digital reading. The method of temperature measurement was used in a previous study. ${ }^{16}$

A questionnaire with open ended questions was used to interview the mother before the discharge from the hospital. The questionnaire included information on the mother's socioeconomic characteristics: age, education, living area, parity, and who supported her and the infant financially and socially. Interviews with the mothers were performed in local languages and then translated into English. An appointment was made with the mother for a home visit before she was discharged from hospital.

During each home visit, which lasted about one hour, the mother was asked about her perception of her own and her baby's health, what health problems she had observed, and what actions she had taken in case of symptoms. She was also asked about her breast feeding pattern and what kind of social support she had at home, if any.

The mother and her infant were examined by the midwife. Further care, counselling, advice, and medical treatment was provided. There was no standardised health education and there was no evaluation of mother's psychosocial situation carried out in this study. If the midwife so assessed, the mother or her infant were referred to the hospital for further medical attention. Field notes were taken by the research midwives on relevant information.

After the home visit at day 42 an appointment was made with the mothers in both Group A and B to come to UTH. The mothers were then examined by a specialist obstetrician and the infants by a specialist paediatrician.

\section{DEFINITION OF VARIABLES}

\section{Health problem}

Any problem related to health identified by the mother herself, or symptoms, signs and diagnosis recorded by the midwife and physicians.

\section{Clinical examination}

(1) Mother: examination of breasts, height of fundus, uterine involution, lochia, signs of excessive bleeding, blood pressure, temperature measurement, assessment of healing of perineal laceration, general health.

(2) Infant: examination of eyes, cord, skin, weight, temperature measurement. Hypothermia was defined as temperature less than $36^{\circ}$.

\section{Breast feeding}

Baby suckling well or not and number of feeds per 24 hours.

Exclusive breast feeding; no extra fluids given to the infant. 
Table 1 Background characteristics of the women

\begin{tabular}{|c|c|c|c|}
\hline Variable & Group $A(n=208) \%$ & Group B $(n=200) \%$ & $p$ Value \\
\hline Age of women (y) & & & NS \\
\hline $14-19$ & $48(23.1)$ & $42(21)$ & \\
\hline $20-29$ & $119(57.2)$ & $103(51.5)$ & \\
\hline $30-39$ & $33(15.9)$ & $48(24)$ & \\
\hline $40-45$ & $3(1.4)$ & $4(2.0)$ & \\
\hline Not known & $5(2.4)$ & $3(1.5)$ & \\
\hline Parity of women & & & $\mathrm{p}<0.05$ \\
\hline Primiparae & $64(31)$ & $42(21)$ & \\
\hline Multiparae & $144(69)$ & $158(79)$ & \\
\hline Women's education (y) & & & NS \\
\hline 0 & $14(6.7)$ & $10(5)$ & \\
\hline $1-7$ & $118(56.7)$ & $115(57.5)$ & \\
\hline $8-12$ & $67(32.2)$ & $72(36)$ & \\
\hline $13-17$ & $5(2.4)$ & $1(0.5)$ & \\
\hline Not known & $4(1.9)$ & $2(1)$ & \\
\hline Husbands'education (y) & & & NS \\
\hline 0 & $2(1.0)$ & $6(3.0)$ & \\
\hline $1-7$ & $55(26.4)$ & $48(24.0)$ & \\
\hline $8-12$ & $84(40.4)$ & $84(42.0)$ & \\
\hline $13-19$ & $26(12.5)$ & $26(13)$ & \\
\hline Not known & $41(19.7)$ & $36(18)$ & \\
\hline Housing area (density) & & & NS \\
\hline Low & $41(19.7)$ & $39(19.5)$ & \\
\hline Medium & $16(7.7)$ & $16(8)$ & \\
\hline High & $151(72.6)$ & $145(72.5)$ & \\
\hline
\end{tabular}

NS=Distributions not statistically significantly different at the $5 \%$ level.

Table 2 Obstetric and infant outcomes in Group $A$ and B (frequencies or means and SD)

\begin{tabular}{|c|c|c|c|}
\hline Variable & Group $A(n=208) \%$ & Group B $(n=200) \%$ & $p$ Value \\
\hline Antenatal data & & & NS \\
\hline Antenatal visits & $5.3(\mathrm{SD}=2.2)$ & $5.5(\mathrm{SD}=2.5)$ & \\
\hline VDRL test & $54(26)$ & $59(29.5)$ & \\
\hline HB measurement & $69(33.2)$ & $76(38)$ & \\
\hline Tetanus toxoid im & $41(19.7)$ & $41(20.5)$ & \\
\hline Duration of labour $(h)$ & & & NS \\
\hline Primipara & $10.39(\mathrm{SD}=4.63)$ & $9.95(\mathrm{SD}=5.09)$ & \\
\hline Multipara & $9.82(\mathrm{SD}=5.17)$ & $9.16(\mathrm{SD}=4.34)$ & \\
\hline Total & $9.98(\mathrm{SD}=5.0)$ & $9.30(\mathrm{SD}=4.5)$ & \\
\hline Episiotomy & & & NS \\
\hline Primipara & $33(51.6)$ & $24(57)$ & \\
\hline Multipara & $6(4.1)$ & $3(1.9)$ & \\
\hline Birth weight $(g)$ & & & NS \\
\hline Boys & $3139(\mathrm{SD}=446)$ & $3068(\mathrm{SD}=352)$ & \\
\hline Girls & $3027(\mathrm{SD}=379)$ & $3040(\mathrm{SD}=336)$ & \\
\hline Total & $3087(\mathrm{SD}=419)$ & $3056(\mathrm{SD}=344)$ & \\
\hline Sex of the newborn & & & NS \\
\hline Girls & $97(46.6)$ & $91(45.5)$ & \\
\hline Boys & $111(53.4)$ & $109(54.5)$ & \\
\hline First breast feeding after birth (h) & & & NS \\
\hline Median & 12.2 & 12 & \\
\hline Range & $(3-48)$ & $(1-48)$ & \\
\hline
\end{tabular}

Cord infection

Signs of discharge, redness.

Eye infection

Signs of discharge, which may be purulent, redness of the eyelids.

Social support person

A person, family member (including husband) or friend who lived with the recently delivered mother during the postpartum period, whom the mother defined as a person with the specific task to assist her during the first 42 days after childbirth.

Action taken to solve a health problem (self care behaviour)

Any type of measures taken in response to perceived health problems.

DATA ANALYSIS

Data analysis was undertaken using the Quest ${ }^{17}$ and SAS software. $\chi^{2}$ Tests, Fisher's exact and $t$ tests were used to compare the two groups. Distributions were considered statistically sig- nificantly different for $\mathrm{p}$ values less than $5 \%$. Field notes were used to supplement results from the quantitative analysis.

ETHICAL APPROVAL

Ethical approval was given by the Research Ethics Committee of the School of Medicine, University of Zambia, Lusaka, Zambia.

\section{Results}

WOMEN LOST TO FOLLOW UP

Eight mothers $(3.8 \%)$ in Group A could not be found on the first home visit (day 3). One 15 year old, single primipara, lost her baby after one week and the mother could not be traced at the time of the subsequent appointment. Other reasons for not finding the mothers were that addresses were incorrect or that the mothers and infants had moved to an unknown place. About $14 \%$ of the mother/infant dyads in group A and B were never found at day 42 . Most of them were multipara and working mothers.

In study Group A, 197 (98.5\%) mother/ infant dyads were visited at home on day 3, 195 $(97.5 \%)$ on day $7,174(87 \%)$ on day 28 , and $178(89 \%)$ on day 42 after childbirth. A total of 7493 person days of follow up was done for mothers and infants in Group A. In Group B, $174(87 \%)$ mothers were home visited at day 42 postpartum. One hundred seventy two $(86 \%)$ of the mothers and infants in Group A and $168(84 \%)$ in Group B attended the postnatal clinic after 42 days at the UTH.

\section{BACKGROUND CHARACTERISTICS}

Table 1 shows the demographic and socioeconomic characteristics. No statistically significant differences were found between the two groups. More than $20 \%$ of the mothers were adolescents. Ninety four per cent of the adolescent mothers lived in the high density area of Lusaka and about half of them lived with a female relative, most often with their own mother. Table 2 shows obstetric and infant outcomes of the mothers and their newborns.

ANTENATAL CARE

Forty three per cent of the mothers had one or more investigations done during the antenatal period as recorded on the antenatal card. The most common test (36\%) was to determine the level of haemoglobin. Only $4 \%$ of all mothers received ferrous sulphate tablets at any time during pregnancy. A total of $113(27.7 \%)$ mothers were tested for syphilis and 2\% were positive. Twenty six per cent of all mothers were given one dose of tetanus toxoid, $28 \%$ two doses, and $20 \%$ of all mothers had received three doses of tetanus toxoid as recorded. There was no significant difference between Group A and B.

\section{DELIVERY CARE}

Median length of labour was 10 hours and the blood loss was assessed by the midwife $(<250$ $\mathrm{ml})$ as normal in both groups. A majority $(54 \%)$ of the primiparas and $3 \%$ of the multiparas had a lateral episiotomy done during delivery. One fourth of all women had 
Table 3 Mothers and infants with one or more health problems as identified by mothers, midwife, and doctors at the end of puerperium

\begin{tabular}{llll}
\hline Variable & $\begin{array}{l}\text { Group } A \\
(n=178) \%\end{array}$ & $\begin{array}{l}\text { Group } B \\
(n=174) \%\end{array}$ & p Value \\
\hline $\begin{array}{l}\text { Mothers with health problem(s) identified by } \\
\text { Mothers }\end{array}$ & $53(29.8)$ & $52(29.9)$ & NS \\
Midwife & $24(13.5)$ & $25(14.4)$ & \\
$\begin{array}{l}\text { Doctor } \\
\text { Midwife's referral of mothers to obstetrician }\end{array}$ & $22(12.4)$ & $24(13.8)$ & NS \\
$\begin{array}{l}\text { Infants with health problem(s) identified by } \\
\text { Mothers }\end{array}$ & $102(57.3)$ & $99(56.9)$ & NS \\
Midwife & $64(35.9)$ & $84(48.3)$ & $\mathrm{p}<0.01$ \\
Doctor & $40(22.4)$ & $48(28.6)$ & $\mathrm{NS}$ \\
Midwife's referral of infants to paediatrican & $30(16.8)$ & $71(41)$ & $\mathrm{p}<0.001$ \\
\hline
\end{tabular}

Table 4 Comparision between mothers'and midwives'identification of one or more health problems in Group A during intervention period

\begin{tabular}{llll}
\hline & \multicolumn{2}{l}{ Group $A$} & \\
\cline { 2 - 4 } Days & Mother's findings & Midwife's findings & p Value \\
\hline Mothers & & & \\
Day 3 $(\mathrm{n}=197)$ & $157(79.7)$ & $84(42.6)$ & $\mathrm{p}<0.001$ \\
Day 7 $(\mathrm{n}=195)$ & $87(44.6)$ & $86(44.1)$ & $\mathrm{NS}$ \\
Day 28 $(\mathrm{n}=174)$ & $53(30.4)$ & $31(17.8)$ & $\mathrm{p}<0.001$ \\
Infants & & & \\
Day 3 $(\mathrm{n}=197)$ & $111(56.3)$ & $112(56.9)$ & $\mathrm{NS}$ \\
Day 7 $(\mathrm{n}=195)$ & $132(67.7)$ & $93(47.7)$ & $\mathrm{p}<0.01$ \\
Day 28 $(\mathrm{n}=174)$ & $155(89.0)$ & $72(41.4)$ & $\mathrm{p}<0.001$ \\
\hline
\end{tabular}

Table 5 Type of maternal health problems reported by the mother in Group $A$ and $B$ at the end of puerperium

\begin{tabular}{llll}
\hline Problem & Group $A(n=178) \%$ & Group B $(n=174) \%$ & $p$ Value \\
\hline Abdominal pain & $25(14)$ & $35(20.1)$ & NS \\
Body pain & $11(6.2)$ & $20(11.5)$ & NS \\
Fever & $5(2.8)$ & $12(6.9)$ & NS \\
Excessive bleeding & $3(1.7)$ & $5(2.9)$ & NS \\
Pain from broken suture line & $1(0.6)$ & $4(2.3)$ & NS \\
Cough & $10(5.6)$ & $2(1.1)$ & p $<0.05$ \\
Other & $10(5.6)$ & $16(9.2)$ & NS \\
\hline
\end{tabular}

Other; diarrhoea, breast abscess, body rash, pain symphysis pubis, dizziness, vomiting, pain on walking, foul smelling lochia, heart palpitation (some mothers had more than one symptom/problem). p Values are for test of proportions.

spontaneous perineal tears. Vaginal tears occurred in $4 \%$ among primiparas and $10 \%$ among multiparas. About $4 \%$ of the infants had a birth weight less than $2500 \mathrm{~g}$. No statistically significant differences were found between the groups.

POSTNATAL CARE

It was observed that all infants were separated from the mothers and placed in a nursery immediately after birth until transferred to the postnatal ward. In the postnatal ward the infants were kept in a separate nursery. Thirty per cent of the mothers reported that they would have preferred to have the baby at the bedside. Median time before the first breast feeding was 12 hours (range 1-48 hours) (table 2 ). Fifteen per cent of the newborns left hospital hypothermic. There was no significant difference between the two groups.

SOCIAL SUPPORT

In Group A, 93\% of the mothers had a "social support" person at home on day 3 after delivery, in most cases a female relative. Twenty per cent reported getting the support from the husband.

On day $42,80 \%$ of all mothers (Group A and B) had a social support person, and in $20 \%$, the husband was the support person at home. In a few cases the social support person was a girl younger than 14 years of age.

MOTHERS AND INFANTS WITH HEALTH PROBLEMS Table 3 shows the number of mothers and infants with health problems in both groups, as perceived by the mother and as observed by the midwife, the obstetrician, and the paediatrician, 42 days after childbirth. There were no significant differences between the two groups in mothers' reports. The midwife and the obstetrician reported fewer mothers with problems compared with what was reported by the mothers themselves. The midwife identified more infants with problems in Group B than in Group A $(p<0.01)$.

In Group A the number of mothers with health problems decreased during the study period while the infants with health problems increased. The percentage of mothers reporting at least one problem decreased from $80 \%$ on day 3 postpartum to $30 \%$ on day 42 . Table 4 shows the mothers' and midwife's finding of number of mothers and infants with one or more health problems in Group A during the intervention period. On day 28 there were more than twice as many mothers reporting infant health problems than identified by the midwife $(p<0.001)$. Not enough breast milk, abdominal pain, general body pain, and pain from the suture line were the most common problems perceived by the mothers. Engorged breasts, fever and offensive lochia were the most common health problems in the mothers reported by the midwife. Poor healing of episiotomies was a problem at day 7 . The midwife identified health problems in about half of the infants on day 3 and day 7 . On day 7, 12\% of the mothers and $15 \%$ of the infants were referred for medical attention.

In all the midwives referred $34 \%$ of the mothers and $32 \%$ of the infants to hospital or health centre during the 42 day period in Group A.

PATTERN OF HEALTH PROBLEMS IN MOTHERS AND INFANTS REPORTED BY MOTHER AND MIDWIFE Tables 5 and 6 show the types of common health problems mothers reported regarding themselves and their infants at the end of puerperium. The most common maternal problem was abdominal pain followed by body pain and fever. The infant health problem pattern was similar in the two groups at day 42 but the total number of symptoms reported by mothers in Group B was higher $(\mathrm{p}<0.01)$. Infant cough/ cold and infants not getting enough breast milk were the most common problems reported by the mothers in both groups at day 42 . Eye discharge and cord infection were more frequent in Group B on day 42.

Table 7 shows maternal health problems identified by the midwife at the 42nd day. There was no difference between the two groups in the pattern of maternal health problems at day 42 reported by the midwife.

Infected cord, infected eyes, and acute respiratory tract infections were more common infant health problems in Group B at the 42 nd day (table 8 ) as identified by the midwife. 
Table 6 Type of infant health problems reported by the mother in Group $A$ and $B$ at the end of puerperium

\begin{tabular}{llll}
\hline Problem & $\begin{array}{l}\text { Group A (n=178) } \\
\text { Number } \%\end{array}$ & $\begin{array}{l}\text { Group B }(n=174) \\
\text { Number } \%\end{array}$ & p Value \\
\hline Cord infection & $0(0)$ & $6(3.4)$ & $\mathrm{p}<0.005$ \\
Eye discharge & $2(1.1)$ & $6(3.4)$ & $\mathrm{NS}$ \\
Cough and/or cold & $44(24.7)$ & $51(29.3)$ & $\mathrm{NS}$ \\
Skin infection & $4(2.2)$ & $3(1.7)$ & $\mathrm{NS}$ \\
Baby warm or cold & $31(17.4)$ & $25(14.4)$ & \\
Other & $19(10.6)$ & $23(13.2)$ &
\end{tabular}

Other; abdominal discomfort, vomiting, diarrhoea, yellow eyes, ear ache, sore mouth (some infants had more than one symptom/problem).

Table 7 Abnormal clinical findings in the mother diagnosed by the midwife in Group $A$ and $B$ at the end of puerperium

\begin{tabular}{llll}
\hline Problem & Group $A(n=178) \%$ & Group B $(n=174) \%$ & $p$ Value \\
\hline Engorged breast & $4(2.2)$ & $2(1.1)$ & NS \\
Broken episiotomy & $2(1.1)$ & $0(0)$ & NS \\
Offensive lochia & $8(4.5)$ & $6(3.4)$ & NS \\
Hypertension & $6(3.4)$ & $11(6.3)$ & NS \\
Fever 37.6 + & $5(2.8)$ & $10(5.7)$ & NS \\
Other & $11(6.2)$ & $12(6.9)$ & NS \\
\hline
\end{tabular}

Other; breast abscess, cough, clinical anaemia, vomiting, recto-vesico vaginal fistula.

Table 8 Abnormal clinical findings of the infant reported by the midwife in Group $A$ and $B$ at the end of puerperium

\begin{tabular}{llll}
\hline Problem & Group A $(n=178) \%$ & Group B $(n=174) \%$ & $p$ Value \\
\hline Infected cord & $2(1.1)$ & $6(3.4)$ & NS \\
Infected eyes & $10(5.6)$ & $17(9.7)$ & NS \\
Acute respiratory infection & $4(2.2)$ & $10(5.7)$ & NS \\
Skin infection & $5(2.8)$ & $11(6.3)$ & NS \\
Fever 37.6 + & $42(23.6)$ & $25(14.4)$ & $\mathrm{p}<0.05$ \\
Other & $15(8.4)$ & $30(17.2)$ & $\mathrm{p}<0.05$ \\
\hline
\end{tabular}

Other; jaundice, dehydrated, oral thrush, diarrhoea, hernia, hypothermia. One infant could have more than one problem reported.

BREAST FEEDING PATTERN

Most of the mothers (90.9\%) in Group A gave additional fluid such as water or other substitute to the newborn during the first six weeks after birth. It was more common at day 7 , that the single adolescent mothers looked after by their female relatives gave extra feeds $(65 \%)$ to the newborn than in the other age groups $(43 \%)(\mathrm{p}<0.01)$. Half of the mothers breast fed 8 to 10 times in 24 hours.

At the postnatal clinic most mothers stated that they were breast feeding. There were significantly more mothers in Group B (16\%) than in Group A (5\%), perceiving insufficient milk production and giving supplementary feedings, $(\mathrm{p}<0.01)$.

MOTHERS' SELF CARE BEHAVIOUR AND HEALTH SERVICES UTILISATION

Seventy per cent of the mothers who reported any health problem such as vaginal bleeding, fever, and abdominal pain, took some action at day 3 , and $61 \%$ at day 7 . Mothers used hot pieces of cotton cloths/compresses to stop bleeding. Fifty six per cent of the mothers, who reported that they had fever at day 3, took panadol or used cold compresses. One mother went to the health clinic because of fever. Three mothers went to the hospital for treatment at day $7(1.7 \%)$. Sixty nine $(53 \%)$ of the mothers reporting abdominal pain treated this with hot compresses $(60 \%)$ or took pain killers (panadol, cafenol), herbs or ampicillin (40\%) day 7 .

Forty eight per cent of the mothers who identified infant problems at day 3 took some action. Twelve of 28 ( $43 \%$ ) who had identified eye discharge cleaned the infant's eyes with water. One mother applied eye ointment. Seven of nine mothers who had identified cord infection cleaned the cord with detol, salt water, or applied vaseline. On day 3,16\% of the mothers had noticed that the infant was "too cold" and half of them covered the infant with a blanket. Half of the mothers who had identified eye infection put breast milk in the infant's eyes day 28.

At day 42, there were more mothers in Group A $(56 \%)$ than in Group B $(41 \%)$ who took actions to solve the infant health problems they had identified $(\mathrm{p}<0.03)$.

MIDWIFE REFERRAL FOR MEDICAL ATTENTION At day 42 , the midwife referred $9 \%$ of the mothers and $17 \%$ of the infants in Group A for medical attention. In Group B, the corresponding numbers were higher, $13 \%$ and $41 \%$. The difference is statistically significant for children $(\mathrm{p}<0.01)$.

\section{THE OBSTETRICIAN'S AND PAEDIATRICIAN'S} DIAGNOSIS

At the end of the postpartum period, the obstetrician found that $13 \%$ of the mothers in Group A had one or more abnormal symptoms, signs or diagnosis. Nine mothers had raised blood pressure, three gastritis, one body rash, four vaginal discharge, two vaginal ulcer, two anal warts, and two vesico-vaginal fistula. The pattern was similar in Group B and 14\% of the mothers had abnormal symptoms, signs or diagnosis. The paediatrician diagnosed health problems in $23 \%$ of the children in Group A and 28\% in Group B. Among infants, respiratory infection was the most common diagnosis in both groups.

\section{INFANT DEATHS}

There were six known infant deaths, two in Group A and four in Group B, during the study period. The cause was unknown in four cases. One was because of diarrhoea and one because of pneumonia, according to the mothers.

\section{Discussion}

The study shows that the mothers in both intervention and control group perceived significantly more health problems than identified by the midwife and doctors. The mothers were more concerned with illnesses and sicknesses and the professionals with diseases. ${ }^{18}$ Illness represents the mother's perceptions of changes in her well being and social function, the human experience, ${ }^{19}$ sickness is related to behavioural and biological signs that are made into symptoms and socially significant outcomes, ${ }^{20}$ and disease as abnormality in the structure and function of body organs and systems, recognised in medical schools and unversities. $^{18} 19$

The obstetrician and the paediatrician focused their observations on the professional expectations related to medical diagnosis, diseases, for example, hypertension, tonsillitis, gastritis, bronchopneumonia, jaundice. The midwife focused mainly on the disease concept, for example, eye and cord discharge, and 
brought in additional midwifery observations, for example, the mother's social situation and relationship with her husband and family.

A typical example from the mothers' perspective, was that mothers experienced insufficient milk production or thought it was good to give extra fluid (water, breastmilk substitute) to the newborn. Significantly more mothers in the intervention group than in the control group abandoned the practice of giving extra fluid, possibly because of the communication they had with the midwife during the postpartum period.

The home visits by a midwife and individual health education and the care given to a mother who had newly delivered reduced infant health problems at the end of the postpartum period, both as perceived by the mothers and as assessed by the midwife. The home visits may have helped mothers take action about their own and infant health problems and to more often use exclusive breast feeding. We can only speculate on the reasons for the positive effects of home visits. The mother may have felt relaxed and more secure when a person with experience in health care paid interest to her and her newborn, not only once but during several home visits. The advice and health education given by the midwife involved the mother both to observe and to take action when she identified a problem.

Most mothers had attended the antenatal care, but the quality of antenatal care was poor. Neither was any special attention paid to the young, single primiparas, who are known to be a risk group. ${ }^{21}$ The proportion of mothers having recommended investigations done during pregnancy-tests for haemoglobin and syphilis and prophylactics of tetanus toxoid-were even lower in this study than in a previous investigation. ${ }^{22}$ As the pregnant women comply with the antenatal care, the staff should take measures to become more professionally efficient.

Some of the postpartum problems such as perineal pain and infection, might have been prevented by improved management of the second stage of labour, and by reducing the number of episiotomies in primipara mothers. ${ }^{23}$

All the infants in this study were separated from their mothers immediately after birth. Maternal/infant skin to skin contact should preferably be encouraged immediately after birth for an early start of breast feeding ${ }^{24}$ and prevention of hypothermia in the newborn. ${ }^{25}$ Low support for early mother/infant contact and breast feeding promotion from the hospital staff, at the time of the study, could be one of the contributing factors to the high number of mothers, giving extra fluids to the newborn during the first weeks after birth. Similar findings from other studies have been reported to be associated with increased incidence of hypothermia, diarrhoea, and acute respiratory tract infections in infants who are not exclusively breast fed. ${ }^{25-27}$ It is known that Zambian mothers in general breast feed for long periods, but little is known about the details of the breast feeding behaviour, or the type and use of supplementary and weaning foods in urban mothers. ${ }^{28}$

A major problem among the newborns during the first weeks of life was eye infection and this was identified both by the mother and the midwife. The aetiology of eye infection is not known, but with the known high prevalence of sexually transmitted diseases in mothers in the region, ${ }^{29}$ precautions regarding gonococci and chlamydial conjunctivitis should be taken. ${ }^{30}$

One quarter of the total number of infants, who were assessed healthy at the time of enrolment in the study, were diagnosed by an experienced paediatrician at day 42 as having a medical health problem, mainly related to infectious diseases. Both the mother and the midwife had assessed significantly more infant health problems than the paediatrician. There could be several explanations for these findings. The midwife might be insecure and thus prone to over-diagnose and therefore have referred an unnecessarily high number of the infants for medical attention. The midwife might need more knowledge on how to assess the degree of a health problem in the infant. The discrepancies between the paediatrician's, the midwife's, and the mothers findings regarding infants' health problems need further investigation. ${ }^{31}$

In Zambia, the tradition to support a newly delivered mother for the first days after childbirth in the home is still strong. We observed that one fifth of the women had their husband as the only social support person. The resources of the support network should be fully utilised and a support person included in the antenatal as well as the intra and postnatal health care of the mothers. Maternal care is about the mother and infant dyad, embracing both the medical and the social aspects and should be emphasised in midwives' and doctors' education. The contribution of the mother's network should also be taken into consideration in overall policy development of maternal and child health programmes. ${ }^{12} 3233$

The high number of maternal and infant health problems reflects the seriousness of the economic and environmental situation in Zambia and the effects of the nutritional shortcomings, and widespread sexually transmitted diseases including HIV/AIDS. ${ }^{14}{ }^{34}$

This also reflects the social status of women in the Zambian society and the neglected needs of women during the postnatal period. ${ }^{35}$ To improve maternal and child health in Zambia it is important to consider the needs of the women in a broader social and economic context.

Several recommendations can be proposed. More attention and consideration should be paid to the puerperium and measures taken to improve the quality of care to newly delivered mothers and newborns. This would include a special attention given to the husbands'/ fathers' role as the main social support person of many urban women. Education on neonatal and infant health, community midwifery, and public health should be reinforced in the nursing/midwifery educational programmes. 
We recommend that the antenatal clinic should develop a programme for quality of care, emphasising preparing and empowering each pregnant woman for motherhood, and advising the mother how to safeguard the health of the fetus and the newborn child. Early start to breast feeding, which should be exclusive, prevention of hypothermia, and prevention of neonatal infections should be brought to the attention of mothers and the social support persons. We also recommend that some of the antenatal visits be extended to early postnatal care to follow up and guide the mother/family. This study was supported by the Swedish Agency for Research
Collaboration with Developing Countries (SAREC), the Collaboration with Developing Countries (SAREC), the
Norwegian Aid Development (NORAD), the Ministry of Norwegian Aid Development (NORAD), the Ministry of Health (MoH) in Zambia, University Teaching Hospital (UNZ), Lusaka, School of Medicine, University of Zambia (UNZA) and Stockholm University College of Health Sciences.
We wish to thank all the mothers and their infants who took part in the study; the staff at UTH who were involved in the home visits and interviews. A special thanks to Professor em G Sterky, IHCAR, Karolinska Institutet, Professor C Chintu, and Dr N
Sikazwe, School of Medicine, University of Zambia for their support and constructive contributions.

1 Moutquin JM, Gagnon R, Rainville C, et al. Maternal and neonatal outcome in pregnancies with no risk factors. Can Med Assoc F 1992;137:728-32.

2 Fauveau V, Stewart K, Khan SA, et al. Effect on mortality of community-based maternity-care programme in rura Bangladesh. Lancet 1991;338:1183-6.

3 Postnatal and Postpartum Care. Appropriate technology following birth. Lancet 1986;ii: 1387-8.

4 Sai FT, Nassim J. The need for a reproductive health approach. Int 7 Gynecol Obstet 1989; suppl 3:103-13.

5 Olds DL, Kitzman H. Can home visitation improve the health of women and children at environmental risk? Pediatrics 1990;86:108-16.

6 Lugina HI, Sommerfeld DMP. Postpartum concerns: A study of Tanzanian mothers. Health Care Women Int 1994; study of Tan:

7 Gjerdingen DK, Froberg D. Predictors of health in new mothers. Soc Sci Med 1991;33:1399-407.

8 Waldenström U. Early discharge after hospital birth. [Dr Med Sc Thesis.] Uppsala: University of Uppsala, 1987.

9 Garcia J, Renfrew M, Marchant S. Postnatal home visiting by midwives. Midwifery 1994;10:40-3.

10 Glazner CMA, MacArthur C, Garcia J. Postnatal care: time for a change. Contemp Rev Obstet Gynaecol 1993;5:130-6.

11 Ghilarducci E, McCool W. The influence of postpartum home visits on clinic attendance. $\mathcal{f}$ Nurse Midwifery 1993;38:152-8.

12 Quigley P, Ebrahim GJ. Women and community health workers promoting community health and development. $\mathcal{F}$ Trop Pediatr 1994;40:66-70.

13 Jaffre Y, Prual A. Midwives in Niger: an uncomfortable position between social behaviours and health care position between social behaviours and

14 Gaisie K, Cross A, Nsemukila G. Zambia demographic and health survey 1992. Lusaka; Department of Social Development Studies, University of Zambia, 1993.
15 Nasah BT, Tyndall $M$. Emerging problems of maternity care in urban settings. In: Nasah BT, Mati JKG, Kasonde JM, eds. Contemporary issues in maternal health care in
Luxembourg: Harwood Academic, 1994;67-87.

16 Christensson K, Siles C, Moreno L, et al. Temperature, metabolic adaptation and crying in healthy full-term newborns cared for skin-to-skin or in a cot. Acta Paediatr 1992; 81:488-93.

17 Gustafsson L. "Quest" - a programme for statistics and epidemiological data analysis. Umeå: University of Umeå, 1985.

18 Sachs L. Introduction to anthropology of medicine. In: Sachs L, Krantz I, eds. Anthropology of medicine and society. A new perspective for a multidisciplinary audience. Stockholm: A new perspective for a multidisciplinary audien

19 Eisenberg L. Disease and illness: Distinctions between professional and popular ideas of sickness. Cult Med Psychiatry 1977;1:9-23.

20 Young A The anthropolgies of illness and sickness. Ann Rev Anthropol 1982;11:257-85.

21 Urassa E, Lindmark G, Nyström L. Maternal mortality in Dar es Salaam, Tanzania: socio-economic, obstetric history and accessibility of health care factors. Afr $\mathcal{F}$ Health $S c i$ 1995;2:242-9.

22 Ransjö-Arvidson A-B, Christensson K, Darkwah G, et al. Maternity care routines in a teaching hospital in Zambia. East Afr Med f 1989;66:427-36

23 Röckner G, Henningsson A, Wahlberg V, et al. Evaluation of episiotomy and spontaneous tears of perineum during childbirth. Scandinavian Fournal of Caring Sciences 1988;2: 19-24.

24 Widström A-M, Ransjö-Arvidson A-B, Christensson K, et $a l$. Gastric suction in healthy newborn infants. Effects on circulation and developing feeding behaviour. Acta Paediatr 1987;76:566-72.

25 Christensson K, Ransjö-Arvidson A-B, Kakoma C, et al. Midwifery care routines and prevention of heat loss in the newborn: A study in Zambia. F Trop Pediatr 1988;34:20812.

26 Ashraf RN, Jalil F, Khan SR, et al. Early child health in Lahore, Pakistan: V. Feeding patterns. Acta Paediatr 1993;390 (suppl):47-61.

27 Victoria CG, Smith PG, Vaughan JP, et al. Infant feeding and deaths due to diarrhoea. A case-control study. Am $\mathcal{F}$ Epidemiol 1989;129:1032-41

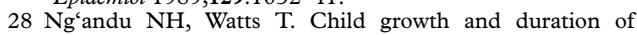
breastfeeding in urban Zambia. I Epidemiol Community Health 1990;44:281-5.

29 Faxelid E, Tembo G, Ndulo J, et al. Individual counselling of patients with sexually transmitted diseases. A way to improve partner notification in a Zambian setting? Sexually Transm Dis 1996;23:289-92.

30 World Health Organization. Management of patients with sexually transmitted diseases. Geneva: WHO Tech Rep Ser, 1991:810.

31 Filippi V, Marshall T, Bulut A, et al. Asking questions about women's reproductive health: validity and reliability of survey findings from Istanbul. Trop Med Int Health 1997;2:4756.

32 Dahlquist G, Sterky G, Ivarsson J-I, et al. Health problems and care in young families - Load of illness and patterns of illness behaviour. Scand f Prim Health Care 1987;5:79-86.

33 World Health Organization. Mother-baby package: implementing safe motherhood in countries. Geneva: WHO/FHE/ MSM/94.11, 1994.

34 Hansson S, Sunkutu RM, Kamanga J, et al. STD care in Zambia: an evaluation of the guidelines for case management through a syndromic approach. Int $f$ STD AIDS 1996;7:A697/1-9.

35 Glazner C, Abdalla M, Russel I, et al. Postnatal care: a survey of patients'experiences. Br F Midwifery 1993;1:67-74. 